\title{
A Study of the Interaction Between Computer- Related Factors and Anxiety in a Computerized Testing Situation (A Case Study of National Open University, Nigeria)
}

\author{
${ }^{1}$ Owolabi J. And ${ }^{2}$ Dahunsi O.R. \\ ${ }^{1}$ Federal College of Education (Technical), Akoka, Lagos, Nigeria \\ ${ }^{2}$ National Open University, Nigeria (NOUN)
}

\begin{abstract}
Computerized testing is becoming popular even in many developing countries like Nigeria. The level of anxiety in a computerized testing situation tends to affect candidates' performance. Studies that investigated factors affecting anxiety in a computerized testing situation appear to be scarce. This study therefore investigated the interaction between some students-related factors (age, gender, year of study, ownership of computer, computer anxiety and computer experience) and test anxiety in a computerized testing situation. The study adopted a correlation design with test anxiety in a computerized testing situation as dependent variable while the student related factors constituted independent variables. Three scales namely: Test Anxiety Scale $(r=0.84)$, Computer Anxiety Scale $(r=0.84)$ and Computer Experience Scale $(r=0.81)$ were used as instruments for data collection. Data collected were analysed using Frequency, Percentages, Pearson Product Moment Correlation (PPMC) coefficient and Multiple Regression analysis. The results of the analysis showed that those with higher computer experience had significant contributions to the variation in test anxiety in a computerized testing situation. Students should therefore be encouraged to have their own computers and use them often in order to reduce test anxiety in a computerized testing situation.
\end{abstract}

\section{KEYWORDS}

Computer-Related, Factors, Anxiety, Computerised, Testing.

\section{INTRODUCTION}

Anxiety refers to a negative emotional response such as worry, fear, apprehension and agitation. According to Scovel (1978), it is a state of apprehension, a vague or sometimes undefined fear. Akman-Yesilel (2012) submits that anxiety is a term used for several disorders that cause nervousness, fear, apprehension and worrying. According to him, these disorders affect the way we feel and behave. Zhang (2004) see it as a cognitive behaviour rising from self doubt and self depreciation. Anxiety is in various forms. State anxiety is characterised as a temporary change in a person's emotional state due to an outside factor, and it is experienced in relation to some particular event or act (Akman-Yesilel, 2012). Unlike state anxiety which is temporary and experienced in relation to a particular event or act; trait anxiety is more permanent and deeply DOI :10.5121/ijite.2014.3103 
International Journal on Integrating Technology in Education (IJITE) Vol.3, No.1, March 2014

rooted in individual's personality. According to Akman-Yesilel (2012), people suffering from this disorder tend to view the world as a dangerous and terrible place. Computer anxiety has been identified as a concept-specific anxiety because it is a feeling that is associated with interaction with computer. Computer anxiety therefore refers to a negative emotional response due to actual or imaginary interactions with computer-based technology and performance on tasks that involve the use of computers. Test anxiety is another anxiety that could be said to be content-specific. Students who have test anxiety feel uneasy, apprehensive or nervous as a result of fear of failing an examination.

According to Spielberg and Vagg (1995), test anxiety has been defined as one element of general anxiety composed of cognitive attentional processes that interferes with competent performance in academic or assessment situations. Duesk (1980) defined it as an emotional state that has physiological and behavioural concomitant and that is experienced in formal testing or other evaluative situations. Test anxiety can take different forms. According to Powers (2001), it can take the form of (i) worry (unwanted negative thoughts about ones performance) or (ii) emotionality (physiological symptoms such as increased heart rate and sweaty palms). But according to Umruh and Lowe (2010), there are four components of test anxiety which are: worry, cognitive interference, emotionality and lack of self confidence. There is however a general concession that worry and emotionality are the two major components of test anxiety that causes distress to both the cognitive and affective domains. According to Lufi, Okasha and Cohen (2004); worry is cognitive distress while emotionality is affective distress.

There have been conflicting reports about the relationship between test anxiety and computer based testing. According to Johnson and Johnson (1981), no relationship exists between computer anxiety, type of test (either computer or paper and pencil) and performance. Contrarily, Vispoel, Rocklin and Wang (1994), found that students generally preferred computerised testing to paper and pencil formats. There is a concern that test performance is linked to computer anxiety. Shermis and Lombard (1998) concluded that examinees feel they may perceive a loss of control over the testing environment which can increase testing anxiety and reduce performance on subsequent tasks.

Computerised testing is becoming popular in Nigeria. Apart from the National Open University of Nigeria (NOUN), some universities now use Computer based testing for post Unified Tertiary Matriculation Examinations. Some professional and International examinations also use computerised testing. Besides, the Joint Admission and Matriculation Board now gives candidates the option of choosing either to sit for the Paper Pencil Test (PPT) or the Computer Based Test (CBT). The percentage of candidates that opted for the CBT in the 2013/2014 Unified Tertiary Matriculation Examinations (UTME) is an indication that majority of the candidates are apprehensive of Computerised testing. Out of a total of 1,664,110 candidates who applied for the examination, 1,629,102 (97.9\%) opted for the Paper Pencil Test, while only 15,008 (2.1\%) opted for the CBT (JAMB, 2013 )

The situation represented by the statistics above showed that all is not well yet, especially at this period when computer is replacing the manual method in virtually all transactions and should be a point of concern for educators especially the computer educators. In particular, the computer educators should be concerned about discovering factors which are likely to influence anxiety in a computerised testing situation, with a view to offering practicable and effective suggestions on how to address the problem. 
International Journal on Integrating Technology in Education (IJITE) Vol.3, No.1, March 2014

Computer experience and computer anxiety have been found to be inversely related, while age is related directly to computer experience (Lian, 2000). On the year of study and test anxiety, Akman Yesilel (2012) found a significant relationship between test anxiety and year of study. Studies investigating computer related factors that could influence anxiety in a computerised testing situation especially in Nigeria are however scarce. Now that computerised testing is becoming more and more popular in our country, such studies are direly needed. It is on this note that this study sought to investigate the influence of selected student related factors (age, gender, year of study, computer experience, computer ownership and computer anxiety) on anxiety in a computerised testing situation.

\subsection{Purpose of the Study}

This study will investigate:

1. The relationship between gender, age, year of study, computer experience, computer ownership, computer anxiety on test anxiety in a computerised testing situation among National Open University of Nigeria (NOUN) students.

2. The combined influence of the six predictor variables (gender, age, year of study, computer experience, computer ownership and computer anxiety) on National Open University of Nigeria students' test anxiety in a computerised testing situation.

3. The relative influence of the six predictor variables (gender, age, year of study, computer experience, computer ownership and computer anxiety) on National Open University of Nigeria students' test anxiety in a computerised testing situation.

\subsection{Research Questions}

The following research Questions were answered:

1. What is the relationship between the six predictor variables (age, gender, year of study, ownership of computer, computer anxiety and computer experience) and test anxiety of students of National Open University of Nigeria in a computerized testing situation?

2. What is the composite effect of the six predictor variables (age, gender, year of study, computer ownership, computer anxiety, and computer experience) on National Open University of Nigeria students' test anxiety in a computerized testing situation?

3. What are the relative effects of the predictor variables (age, gender, year of study, computer ownership, computer anxiety, and computer experience) on National Open University of Nigeria students' test anxiety in a computerized testing situation?

\subsection{METHODOLOGY}

\subsection{Research Design}

This is a descriptive survey research, which sets out to investigate the relationships among age, gender, year of study, computer ownership, computer anxiety and computer experience and test anxiety in a computerized testing situation. It also investigates the combined and relative contributions of the predictor variables (age, gender, year of study, computer ownership, computer anxiety and computer experience) to the variance in test anxiety in a computerized testing situation. 
International Journal on Integrating Technology in Education (IJITE) Vol.3, No.1, March 2014

\subsection{Population of the Study}

The target population of this study is the National Open University (NOUN) students in Lagos State, Nigeria.

\subsection{Sample and Sampling Techniques}

The study adopted purposive sampling. Out of the two major centres in Lagos State (Apapa and Ikeja), Apapa was used for the trial testing of the instrument used for the study. The Ikeja centre was therefore selected for the study. At the Ikeja centre, those in 400, 500, 600 and 700 levels that had experience in computerized testing were selected for the study. A total of 424 questionnaires were distributed to the students that were available and signified their willingness to participate in the study. 385 returned the completed questionnaire, 39 did not. The return rate was therefore $90.8 \%$.

\subsection{Research Instruments}

Three instruments were used in the study, namely:

1. Test Anxiety Scale 2. Computer Anxiety Scale 3. Computer Expérience Scale

\subsection{Validity of the Instrument}

The three scales were adapted by the researchers. Three other people validated it. The corrections from their constructive criticisms were effected before the trial testing.

\subsection{Reliability of the Instrument}

The instruments were trial tested on one hundred (100) NOUN students in Apapa Centre. The Cronbach alpha was used to determine the reliability coefficients of the scales with the aid of Statistical Package for Social Sciences (SPSS) version 17.0. The reliability coefficients of the scales were as follows:

Table 1: Reliability Coefficients of Test Anxiety, Computer Anxiety and Computer Experience Scales

\begin{tabular}{|l|l|l|}
\hline S/N & Scale & Reliability \\
\hline 1 & Test - anxiety scale & 0.84 \\
\hline 2 & Computer anxiety scale & 0.84 \\
\hline 3 & Computer experience scale & 0.81 \\
\hline
\end{tabular}

The high reliability coefficients as shown in the table above shows that the scales were fit for the study in Nigeria.

\subsection{Method of Data Collection}

The researchers engaged five research assistants (one from each of the five schools used). One research assistant was used for each of Education, Law, Science, Arts and Social Science and 
International Journal on Integrating Technology in Education (IJITE) Vol.3, No.1, March 2014

Business Schools. They handled the administration of the questionnaire for their respective schools.

\section{RESULT}

The results and relevant discussions are presented below in accordance with the hypotheses raised.

\section{Background Information of Respondents}

The composition of the respondents by age, gender, year of study and computer experience are as follows: Majority of the NOUN students that participated were 26 - 40 years old (55.3\%), 27.0 $\%$ were between age 16 - 25 years of age. A few of them (17.6\%) were $41-60$ years of age.

On their gender, majority were males $(54.6 \%)$, females were also sizeable in number $(45.5 \%)$. On their years of study, $39.0 \%$ were 400 levels, $21.6 \%$ were 500 levels, $23.2 \%$ were 600 levels, and $16.4 \%$ were 700 levels. $66.5 \%$ own a computer while $33.5 \%$ did not have a computer.

Table 2: Correlation Matrix Showing the Relationship between Noun Students' Test Anxiety in a Computerized Testing Situation and the Predictor Variables.

\begin{tabular}{|l|l|l|l|l|l|l|l|}
\hline & Age & \multicolumn{1}{|c|}{ Gd } & \multicolumn{1}{|c|}{ YS } & CO & CA & CE & TA \\
\hline Age & 1.000 & & & & & \\
\hline Gd & .005 & 1.000 & & & & & \\
\hline YS & $.295^{* *}$ & -.007 & 1.000 & & & & \\
\hline CO & 0.032 & 0.030 & 0.067 & 1.000 & & & \\
\hline CA & -0.037 & $-0.198^{* *}$ & -0.084 & 0.028 & 1.000 & & \\
\hline CE & -0.070 & 0.020 & 0.053 & -0.182 & $-0.373^{* *}$ & 1.000 & \\
\hline TA & -0.042 & -0.134 & -0.014 & 0.103 & $0.517^{* *}$ & -0.345 & 1.000 \\
\hline Mean & 1.87 & 1.52 & 2.10 & 1.30 & 1.10 & 17.32 & 14.39 \\
\hline S.D & .639 & .500 & 1.137 & .466 & .327 & 5.037 & 3.802 \\
\hline
\end{tabular}

KEY: Gd = Gender, YS = Year of Study, $\mathrm{CO}=$ Computer Ownership, CA = Computer Anxiety, CE = Computer Experience, $\mathrm{TA}=$ Test Anxiety, $\mathrm{SD}=$ Standard Deviation.

$* *$ = correlation is significant at the 0.01 level (2 tailed)

$*=$ correlation is significant at the 0.05 level ( 2 tailed $)$

Table 3a: Multiple Regressions of the Predictor Variables on Test Anxiety in a Computerized Testing Situation.

\begin{tabular}{|l|l|}
\hline Parameter & Value \\
\hline Multiple Regression $®$ & 0.581 \\
\hline R - Square & 0.338 \\
\hline Adjusted R - Square & 0.326 \\
\hline Std Error of Estimate & 3.0604 \\
\hline
\end{tabular}


International Journal on Integrating Technology in Education (IJITE) Vol.3, No.1, March 2014

Table 3b: Multiple Regression ANOVAs Table

\begin{tabular}{|l|l|l|l|l|l|}
\hline Model & Sum of square & Df & Mean square & F & Sig. \\
\hline Regression & 2195.008 & 6 & 365.835 & 28.170 & $.000^{\mathrm{a}}$ \\
Residual & 4298.518 & 331 & 12.986 & & \\
Total & 6493.527 & 337 & & & \\
& & & & & \\
\hline
\end{tabular}

a. Predictors: (constant), age, gender, year of study, computer ownership, computer anxiety and computer experience

b. Dependent variable: test anxiety in a computerized testing situation.

Table 4: Coefficients Indicating Relative Effects of the Predictor Variables on NOUN Students' Test Anxiety in a Computerized Testing Situation.

\begin{tabular}{|l|l|l|l|l|l|l|}
\hline Model & \multicolumn{2}{l|}{$\begin{array}{l}\text { Unstandardized } \\
\text { Coefficients }\end{array}$} & $\begin{array}{l}\text { Standardized } \\
\text { coefficient }\end{array}$ & & P - Value & Remark \\
\hline & B & Std. Error & Beta & T & & \\
\hline Constant & 14.511 & 2.062 & & 7.039 & .000 & \\
\hline Age & -.314 & .325 & -.046 & -.966 & .335 & N.S \\
\hline Gd & -.575 & .403 & -.066 & -1.426 & .155 & N.S \\
\hline YS & .115 & .181 & .030 & .635 & .526 & N.S \\
\hline CO & .909 & .429 & .097 & 2.120 & .035 & S \\
\hline CA & .320 & .035 & .459 & 9.140 & .000 & S \\
\hline CO & -.186 & .055 & -.170 & -3.412 & .001 & S \\
\hline
\end{tabular}

KEY: $\mathrm{Gd}=$ Gender, YS $=$ Year of Study, $\mathrm{CO}=$ Computer Ownership, $\mathrm{CA}=$ Computer Anxiety, $\mathrm{CE}=$ Computer Experience, $\mathrm{TA}=$ Test Anxiety, $\mathrm{SD}=$ Standard Deviation.

a. Dependent Variable: Test Anxiety.

The Pearson Product Moment Correlation Matrix showed that four of the predictor variables out of six had statistically significant relationship with test anxiety in a computerized testing situation. Specifically, the relationship between computer anxiety and test anxiety in a computerized testing situation is fairly high and statistically significant $(r=0.517, p<0.05)$. This implies that those with high computer anxiety have high test anxiety in a computerized testing situation. The relationship between ownership of computer and test anxiety in a computer testing situation is positive, weak but statistically significant $(\mathrm{r}=0.103, \mathrm{P}<0.05)$. In the analysis, computer ownership is coded 1 while non - ownership is coded 2, this implies that those that do not own computer had higher anxiety. The correlations between gender $(\mathrm{r}=-0.134, \mathrm{P}<0.05)$, computer experience $(\mathrm{r}=-0.345, \mathrm{P}<0.05)$ and test anxiety in a computerized testing situation are negative, weak and statistically significant. For gender, male was coded 1 while female was coded 2, negative relationship between gender and test anxiety in a computer testing situation therefore implies that male students possessed higher test anxiety compared to their female counterparts. Computer experience was seen to relate negatively with test anxiety in a computerized testing situation. The implication is that those with higher computer experience had lower test anxiety in a computerized testing situation compared to their counterparts. 
International Journal on Integrating Technology in Education (IJITE) Vol.3, No.1, March 2014

The multiple regression correlation coefficient (R) showing the linear relationship between the six predictor variables (age, gender, year of study, computer ownership, computer anxiety and computer experience) and test anxiety of NOUN students in a computerized testing situation is 0.581 . The adjusted $\mathrm{R}$ square value is 0.326 . This implies that the variation in test anxiety in a computerized testing situation accounted for by the stated predictor variables (sex, age, year of study, computer ownership, computer anxiety and computer experience) is $32.6 \%$.

As shown in table $3 \mathrm{~b}$ above, further verification using multiple regression ANOVA produced $\mathrm{F}$ ratio $=28.170, \mathrm{P}<0.05$. This implies that there is a significant linear relationship between the above stated predictor variables (age, gender, year of study, computer ownership, computer anxiety and computer experience) and test anxiety in a computerized testing situation.

Table 4 above showed the relative effects of the predictor variables (age, gender, year of study, computer ownership, computer anxiety and computer experience) on NOUN students' test anxiety in a computerized testing situation indicated by standardized Beta $(\beta)$ weights. Computer anxiety contributed most, directly and significantly to test anxiety in a computerized testing situation $(\beta=0.459, \mathrm{t}=9.140, \mathrm{P}<0.05)$. The contribution of computer ownership is next to that of computer anxiety $(\beta=0.097, \mathrm{t}=2.120, \mathrm{P}<0.05)$. The contribution of computer ownership is also positive and statistically significant though weak. The contribution of year of study is also positive but weak. It is also statistically not significant $(\beta=0.030, \mathrm{t}=0.635, \mathrm{P}>0.05)$. The contribution of computer experience to test anxiety in a computerized testing situation is negative, weak but statistically significant $(\beta=-0.170, \mathrm{t}=3.412, \mathrm{p}<0.05)$. The contributions of age and gender are negative, weak and statistically insignificant.

\section{DISCUSSION OF FINDINGS}

The study revealed that computer anxiety related significantly with test anxiety in a computerized testing situation. The implication is that those with high computer anxiety also have high test anxiety in a computerized testing situation. Reduced computer anxiety would imply reduced test anxiety in a computerized testing situation. This agrees with some studies by Gressard and Loyd, (1986) and Fletcher and Deeds (1994). In both studies computer anxiety, lack of confidence and lack of enjoyment influence both acceptance of computers and their use as a teaching and learning tool. For improved performance in a computerized testing situation frantic efforts should therefore be made to reduce the level of computer anxiety of NOUN students. The study also showed that those that own computer had lower test anxiety in a computerized testing situation. This could be because ownership of computer encourages frequent usage which in turn decreases anxiety and also test anxiety in a computerized testing situation.

The result showed that the combined contribution of the six predictor variables (age, gender, year of study, computer ownership, computer anxiety and computer experience) to variance in test anxiety in a computerized testing situation is $32.6 \%$. The linear relationship between the predictor variables and test anxiety in a computerized testing situation is also statistically significant. These predictor variables are therefore relevant in the prediction of NOUN students' test anxiety in a computerized testing situation. This is also in agreement with studies that have shown that computer anxiety, lack of confidence and lack of enjoyment influence both acceptance of computer and their use as a teaching and learning tool (Gressard \& Loyd, 1986; Fletcher \& Deeds, 1994). 
International Journal on Integrating Technology in Education (IJITE) Vol.3, No.1, March 2014

The study revealed that the contributions of computer anxiety and computer ownership contribute significantly to the variation in NOUN students' test anxiety in a computerized testing situation. The implication is that for an effective computerized testing, the candidates should each possess their own personal computers and should also be helped to overcome computer anxiety.

\section{CONCLUSION}

The findings from this study showed that reduced computer anxiety as well as computer ownership would reduce test anxiety in a computerized testing situation. With the popularisation of CBT, students should be encouraged to own personal computer. For improved performance in a computerized testing situation frantic efforts should therefore be made to reduce the level of computer anxiety of the NOUN students. Periodic free training could be given to students to help eliminate the problem of test anxiety in a computerised testing situation.

\section{REFERENCES}

[1] Scovel, T. (1978). The effect of affect on Foreign Language Learning: A review of the anxiety research. Language Learning, 28, 129-142.

[2] Akman Yesilel D.B (2012). Test Anxiety in ELT Classes. Frontiers of Languge and Teaching, 3, 24-31.

[3] Zhang, Y.X. (2004). A Study of the candidates'test anxiety in the CET-SET context. MA Dissertation, Chongqing University.

[4] Spielberg, C.D and Vagg, P.R. (1995). Test anxiety: A transactional process model. In Spielberg C.D. and Vagg, P.R (eds). Test Anxiety:Theory, Assessment and Treatment. Washington, D.C,:Taylor and Francis.

[5] Duesk, J.B. (1980). The development of test anxiety in children. In I.G. Sarason (Ed.). Test anxiety: Theory, research and applications pp 87-110. Hillsdale, NJ: Erlbaum.

[6] Powers D. E (2001). Test Anxiety and Test Performance: Comparing Paper Based and computeradaptive versions of Graduate Record Examinations (GRE) General Test. Journal of Educational Computing Research, 24, 249-273.

[7] Unruh, S.M. and Lowe, P.A. (2010). The development and validation of a Spanish Language version of the test anxiety inventory for children and adolescents. Hispanic Journal of Behavioural Sciences, 32(1), 164-183.

[8] Lufi,D., Okasha, S., Cohen, A. (2004). Test anxiety and its effect on the personality of students with learning disabilities.Learning Disability Quarterly, 27(3), 176-184.

[9] Johnson H.J and Johnson K.N (1981). Psychological considerations in the development of Computerised testing situations. Behavioural Research Methods and Instrumentation, 13, 421-424.

[10] Vispoel, W.P., Rocklin, T.R and Wang, T. (1994). Individual differences and test administration procedures: A comparison of field item, computerised-adaptive, and self-adapted testing. Applied Measurement in Education, 7, 53-79.

[11] Shermis, M.D. and Lombard, D. (1998). Effects of Computer-Based tset Anxiety and Performance. Computers in Human Behaviour, 14, 111-123.

[12] JAMB (2013). JAMB Releases 2013 UTME results, withholds 12,011 results; retrieved from www.ournaira.com on 7th May, 2013.

[13] Gresssard C.P and Loyd, B.H (1986). The nature and correlates of computer anxiety in college students. Journal of Human behaviour and Learning, 2(2), 45-52.

[14] Fletcher, W.E and Deeds, J.P (1994). Computer anxiety and other factors in predicting computer use among United States secondary bagricultural educators. Journal of Agricultural Education, 35(2), 1621. 
International Journal on Integrating Technology in Education (IJITE) Vol.3, No.1, March 2014

\section{Authors}

Josiah Owolabi, is currently a Principal Lecturer and the Head of Mathematics/Statistics Department at the Federal College of Education (Technical), Akoka, Lagos, Nigeria. He holds a B.Sc(Ed) and M.Sc in Mathematics. He is currently a research student at the Institute of Education, University of Ibadan, Nigeria. His previous work experience before the present appointment includes teaching Mathematics, Further Mathematics and Computer in a secondary School.Josiah has about 20 publications in local and international Journals. He had also authored/co-authored three textbooks in Mathematics

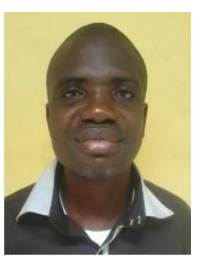
and one in Computer Studies. His research interests are: Mathematics and Computer Education. E-mail: josiahowolabi@yahoo.com

Dahunsi Oludamilola Oluseun Ruth works as a database administrator (DBA) at the National Open University of Nigeria (NOUN) headquater, Victoria Island, Lagos, Nigeria. Her work experience includes collating and generating students result, providing technical supports for students using administrative portal and Facilitation Monitoring. She is also involved in invigilating nursing clinical examination and providing technical support for eexamination. Before her employment at NOUN, her previouus work experience include: Technical assisstant at the Apostolic Faith Mission Electronic Department, Assistant

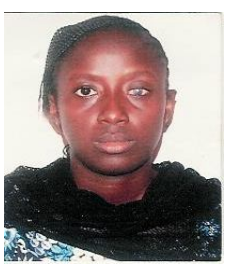
Lecturer Computer science, Federal Polytechnic Nekede Owerri, Imo State, among others. 